\title{
UPAYA PEMBERDAYAAN MASYARAKAT MELALUI PENGHIMPUNAN DANA KOINISASI DI DESA NGRONGGOT KECAMATAN NGRONGGOT KABUPATEN NGANJUK
}

\author{
Moh. Hasyim Afandi, Zainal Arifin dan Tri Wahyudi Ramdhan \\ STAI Miftahul Ula Nglawak Kertosono Nganjuk, Indonesia \\ STAI Darul Hikmah Bangkalan, Indonesia \\ m.hasyim.afandi@gmail.com, zainalarifin061169@gmail.com, \\ wahyudi@darul-hikmah.com
}

\begin{abstract}
Nahdlatul Ulama, the majority of whose members are mostly from the lower class, initiated to collect coins from members. All members are asked to participate. Therefore Board of Management of Nahdlatul Ulama Nganjuk regency launched the NU Caring Coin Movement program. It is the movement of NU members to collect coins from the homes of residents of Nahdliyin whose benefits are to solve various problems in aspects of life and realize the independence of jam'iyyah. The results of the mentoring activities obtained were first, the condition of Ngronggot village society before the mentoring although the spirit of diversity and social solidarity was very high but still individual. Second, The form of the assistance activities carried out included awareness of their potential so that they always think positively, and vocational training the following applications so that new interpreneurs emerge. Third, after the mentoring program is complete, community trust in self potential, both economic and religious, emerges together to support each other both in religious and social activities.
\end{abstract}

Keywords: Pemberdayaan, Penghimpunan, Koinisasi 


\section{Latar Belakang}

Di lingkungan masyarakat kita mengenal istilah uang receh 100,200,500, dan 1000 rupiyah yang sering disebut koin adalah alat tukar yang kurang bernilai manakala hanya satu. Akan tetapi nilainya akan sangat besar jika terkumpul dalam jumlah yang sangat banyak. Apalagi jika melibatkan seluruh warga masyarakat tentu jumlahnya akan sangat besar.

Sebenarnya, model ini sudah dilakukan masyarakat sejak jaman dahulu, dalam bentuk jimpitan beras yang diambil setiap malam oleh petugas ronda. Meskipun hanya 2 sampai 5 sendok tiap keluarga, akan tetapi jumlah keluarga dalam satu komunitas (mis. RT) cukup banyak dan dilakukan setiap hari, maka beras yang terkumpul juga banyak. Dan dari jimpita itu, warga bisa membantu warga yang sakit, menyantuni anak yatim, membeli sarana umum dan lain-lain.

Bertolat dari fakta ini,Nahdlatul Ulama yang mayoritas anggotanya sebagian besar berasal dari kalangan masyarakat bawah menggagas menghimpun koin dari anggota. Tidak pandang kaya atau miskin semua anggota diminta berpartisipasi. Dan ternyata di beberapa Cabang NU berhasil menghimpun koin dalam jumlah yang sangat fantastis. Di Cabang NU Sragen pada akhir tahun 2017 terkumpul 3,3 
M, di Cabang Bantul, yang dikenal sebagai basis Muhammadiyah dalam 6 bulan terhimpun 1.2 M. Ini menunjukkan bahwa NU adalah organisasi yang betul-betul memiliki ummat.

Atas dasar itulah PC NU kabupaten Nganjuk menccanangkan program Gerakan Koin NU -Peduli. Yakni gerakan warga NU untuk mengumpulak uang receh dari rumah warga nahdliyyin yang manfaatnya untuk solusi berbagai persoalan dalam aspek kehidupan dan mewujudkan kemadirian jam'iyyah.

\section{Gambaran Umum Situasi Komunitas Dampingan}

Desa Ngronggot kecamatan Ngronggot terletak di sebelah tenggara kabupaten Nganjuk dengan luas wilayah 976 ha teridir dari 572 ha daratan/tegalan dan 404 ha sawah pertanian subur. Terbagi menjadi lima dusun. Dusun Ngronggot Krajan, dusun Dingin, dusun Brumbung, dan dusun Tempel.

Jumlah penduduk 11.432 jiwa dengan komposisi 5030 laki-laki dan 6402 perempuan. Dengan usia produktif 8.650 0rang. Dari jumlah tersebut 12.425 beragama Islam dan selebihnya beragama Katolik. Masyarakat desa Ngronggot mayoritas berpendidikan SLTA ke bawah, hanya sekitar $20 \%$ sarjana. Mata pencahariannya mayoritas $75 \%$ petani dengan komposisi buruh tani $60 \%$ dan $40 \%$ petani pemilik lahan. Yang 
$25 \%$ terbagi menjadi pedagang, pengusaha, pegawai, TNI, buruh perusahaan.

Di desa Ngronggot terdapat 6 masjid, 45 mushola, 5 SDN, 1MIN, 1 MIS, 1 MTSS,1 SMPN, MAS, 2 pondok pesantren, 3 TPQ , 8 majelis taklim. Di masing-masing masjid telah terbentuk Laz untuk menghimpun dan membagikan zakat dan sedekah dari masyarakat di sekitarnya.Untuk sekolah tingkat dasar antara madrasah dan SDN mridnyaberimbang. Untuk sekolah tingkat SMP/MTS dan SLA mayoritas warga bersekolah di luar desa Ngronggot. Sedangkan TPQ, saantrinya berkisar antara 50 s.d. 100 anak. Para santri ada yang belajar TPQ AL-HIDAYAH di dusun Kedunglo . Majelis taklim terdiri dari bapak-bapat dan ibu-ibu dengan waktu yang berbeda. Khusus majelis taklim dusun Kedunglo dibagi 6 kelompok yang masing-masing kelompok diikiti antara 75 sampai dengan 145 orang dan ini wajib, karena yang tidak mengikuti majelis taklim bila keluarganya meninggal tidak dibacakan fida (surat Ihlas sebanyak 100.000 yang dibaca selama 7 hari ). Sedangkan majelis taklim yang lain bersifat suka rela, baik bapakbapak maupun ibu-ibu sehingga pesertanya tidak terlalu banyak .

\section{Kondisi Saat Ini Masyarakat Dampingan}

Kesadaran beragama masyarakat desa Ngronggot sangat 
beragam. Walaupun hampir semua penduduk desa Nronggot beragama Islam, namun belum semuanya melaksanakan ibadah. Diperkirakan hanya $75 \%$ yang beribadah dan hanya $50 \%$ yang aktif ke masjid. Demikina pula yang berpuasa dan berzakat. Meskipun mampu/kuat masih banyak yang tidak berpuasa. Dalam berzakat, ada kecenderungan untuk membagi sendiri kepada asnaf yang dipilih sesuai dengan keinginannya. Di samping itu juga banyak yang belum berzakat. Khusus untuk dusun Kedunglo mayoritas zakatnya dikumpulkan pada LAZ yang dibentuk dari para muzakki sendiri. Namun masih ada juga yang zakatnya disisihkan untuk dibagi sendiri. Di samping itu, kesadaran untuk bersedekah di Ngronggot cukup tinggi. Di sini dapat dilihat pada saat ada pengumpulan dana untuk kegiatan, baik kegiatan rutin maupun insidental (seperti mengadakan pengajian umum atau mengadakan kegiatan pembangunan sarana ). Kesadaran bersedekah ini akan bisa maksimal manakala ada sentuhan-sentuhan program berupa pemberdayaan masyarakat. Pandangan masyarakat tentang tingkat kesalehan seseorang bagi kebanyakan masyarakat desa Ngronggot diukur dari kualias ibadah syahsyiyahnya (kekewajiban yang wajiban bersifat pribadi, seperti shalat, puasa, haji ) dari pada ibadah ijtima'iyyah (kewajiban bersifat sosial). 
Masyarakat desa Ngronggot kecamatan Ngronggot kabupaten Nganjuk 99,9 \% beragama Islam yang berpaham ahluussnnah waljama'ah yang notabene Nahdlatul Ulama dengan latar belakang pendidikan agama (madrasah dan pondok pesantren) dan pendidikan umum dan latar belakang ekonomi menengah ke bawah.

Dalam bidang ekonomi, masyarakat cenderung berusaha sendiri. Belum ada kelompok/organisasi yang secara nyata mampu memberdayakan ekonomi masyarakat karena keterbatasan modal. Beberapa kali pemerintah memberikan program pemberdayaan seperti koperasi,PNPM, BUMIDES, pokmas dan lain-lain. Akan tetapi sampai saat ini belum menampakkan hasil yang menggembirakan.

Tidak maksimalnya keterlibatan pemerintah desa Ngronggot terhadap kegiatan keagamaan sangat terasa, sehingga terkesan, para tokoh dalam menangani kegiatan berjalan sendiri-sendiri. Dukungan pemerintah, berupa tidak mengganggu/melarang kegiatan-kegiatan keagamaan dan menghadiri acara-acara yang diselenggarakan masyarakat. Pada hal kalau disadari, jika masyarakatnya baik maka otomatis roda pemerintahan akan berjalan dengan baik pula. Dan jika mau, pemerintah desa bisa mengintervensi kegiatan dalam bentuk anggaran yang disisihkan dari dana desa. Solusinya mengadakan

Vo1. 2 No. 1, April 2020
Moh. Hasyim Afandi, Dkk | 68 gurnal Pengabdian Masyarakat 
audiensi dan pendekatan kepada kepala desa Ngronggot beserta perangkatnya agar dalam penyusunan APBDes melibatkan tokoh-tokoh agama dan menyediakan anggaran untuk kegiatan-kegiatan agama dan sosial

Latar belakang pendidikan. Latar belakang pendidikan ini sangat berpengaruh pada sikap warga masyarakat terhadap masalah yang timbul di masyarakat. Warga masyarakat yang berpendidikan pesantren cenderung kurang terbuka terhadap gagasan-gagasan baru yang muncul di masyarakat, sehingga gagasan tersebut sering tidak bisa berjalan karena tidak diakomodasi. Di samping itu pendidikan yang rendah juga berpengaruh pada cara berpikir warga yang cenderung apa adanya. Solusinya mengadakan sosialisasi dan audiensi pada tokohtokoh agama akan pentingnya pemberdayaan masyarakat.

Mata pencaharian warga Sebagaimana dikemukakan di depan, bahwa masyarakat desa Ngronggot sebagian besar bertani. Mayoritas masih petani tradisional dan yang ditanam bergantian antara padi dan jagung, sebagian ada yang menanam sayur (kacang panjang, terung, sawi, kangkung) dan ada yang menanam buah (melon, semangka). Dari sistem bertani semacam ini perngahasilan yang didapat tentu tidak terlalu besar. Mengadakan pertemuan dengan para petani dengan 
menghadirkan para ahli pertanian dan petani berpengalaman untuk memberikan penyuluhan pertanian modern dan diversifikasi pertanian sehingga para petani dapat meningkat pendapatnnya.

Perbedaan pemahaman makna zakat dan sedekah. Di kalangan masyarakat masih banyak ditemukan perbedaan pemahaman makna zakat. Ada sebagian masyarakat yang memahami bahwa harta yang wajib dizakati dari hasil pertanian adalah yang beruka makanan pokok, sedangkan yang bukan makanan pokok tidak wajib dizakati, termasuk yang tidak wajib adalah zakat profesi. Akibatnya perolehan zakat kurang maksimal. Adapun pemahaman tentang makna sedekah dimaknai kalau ada kelebihan bersedekan kalau tidak ya tidak bersedekah. Solusinya sering dilakukan halaqoh dengan ulama sehingga dicapai kesepahaman tentang zakat dan sedekah

Belum ada organisasi yang mampu menggerakkan potensi masyarakat Sampai saat ini belum ada organisasi yang mampu menggerakkan potensi masyarakat sehingga pengumpulan dana masih bersifat parsial, secara kelompok dan sesuai dengan kebutuhan. Masyarakat secara berkelompok akan melakukan pengumpulan dana manakala ada kegiatan yang perlu didanai. Solusinya bekerjasama dengan organisasi massa dalam hal ini Nahdlatul Ulama melalui 


\section{LAZIZNU.}

\section{Strategi Pelaksanaan Program}

Strategi adalah penentuan dari tujuan dasar jangka panjang dan sasaran sebuah perusahaan, dan penerimaan dari serangkaian tindakan dan alokasi dari sumber-sumber yang dibutuhkan untuk melaksanakan tujuan tersebut. Dari definisi ini jelas bahwa tujuan merujuk pada hasil akhir sedangkan strategi merujuk pada cara yang ditempuh untuk mencapai hasil akhir.

Setiap kegiatan pasti memerlukan strategi untuk mencapai tujuan yang diinginkan. Adapun strategi pencapaian program meliputi

\section{Perencanaan}

Perencanaan dilakukan dengan mengadakan pertemuan penulis dengan PC LAZIZNU kabupaten Nganjuk untuk merumuskan kegiatan yang akan dilaksanakan. Pertemuan dilakukan beberapa kali untuk memaksimalkan program

\section{Pengorganisasian}

Pengorganisasian adalah langkah pengaturan agar program berjalan sesuai dengan harapan dan tidak tumpang tindih. Dalam pengorganisasian ini dilakukan penentuan siapa penanggungjawabnya, berapa biayanya, penentuan tahapan-tahapan pelaksanaan, penentuan 
sasaran, dan penentuan nara sumber

\section{Pelaksanaan}

Pelaksanaan dilaksanakan sesuai dengan program yang dicanangkan dalam pengorganisasian dengan memperhatikan kondisi setempat ( tempat, waktu, biaya, sasaran ) sehingga program dapat terlaksana dengan baik dengan mendapat dukungan penuh dari peserta dan menghasilkan aut put yang memuaskan

\section{Pemantauan /control}

Pemantauan/kontrol. Ini dilakukan agar pelaksaan program tidak melenceng dari rencana. Setiap tahap pelaksanaan program selalu dikontrol sehingga apabila ditemukan kesalahan, baik yang berhubungan dengan penanggung jawab, peserta, biaya maupun yang lain, segera dapat diperbaiki sesuai dengan rencana.

\section{Evaluasi,}

Evaluasi. Kegiatan ini sebagai upaya untuk mengetahui apakah program yang dicanangkan sesuai atau tidak dengan pelaksanaannya serta hasil yang dicapai. Adapun stakeholders dalam kegiatan ini adalah (a) Aparat pemerintah setempat, (b) Tokoh masyarakat, (3) nara sumber, (4) PC LAZIZNU kabupaten Nganjuk 


\section{Pelaksananaan}

Setelah melaksanakan pendampingan bersama LAZIZNU selama tiga bulan, yakni buan Januari 2019 s.d. Maret 2019, ada beberapa kegiatan yang dilakukan dalam kegiatan pendampingan dengan rincian sebagai berikut:

1. Sosialisasi program kepada warga masyarakat desa Ngronggot

Sosialisasi program kepada warga masyarakat desa Ngronggot dilakukandi lima titik. Penentuan lima titik atas dasar dusun. Dalam sosialisasi disampaikan latar belakang kegiatan ,tujuan kegiatan, manfaat kegiatan, sasaran kegiatan, bentuk kegiatan, penanggung jawab kegiatan, pelaksana kegiatan, dan biaya kegiatan

2. Pembentukan pengurus/penanggung jawab

Pembentukan pengurus/penaggung jawab. Setelah sosialisasi langsung dibentuk pengurus/penanggung jawab. Dalam pemilihan ini melibatkan pengurus anak ranting NU sehingga kegiatan ini inklude dengan kegiatan jam'iyyah Nahdlatul Ulama.

Dengan komposisi sebagai berikut :

Penaggung jawab : PC NU kab. Nganuk

Dewan syar'i : LBMNU

Pengawas : : PCNU dan Pemerintah desa Ngronggot 
Operasional

Koordinator

Pelaksana
: PC LAZIZNU kab. Nanjuk

: MWC Ngronggot

: Pengurus Ranting NU desa Ngronggot dibantu pengurus anak ranting di dusun seluruh desa Ngronggot dan petugasn Koin.

3. Penetuan petugas lapangan

Penentuan petugas lapangan. Yakni menunjuk orang yang bertugas membagi dan mengumpulkan kaleng koin. Baik pengurus maupun petugas kaleng koin, melaksakan kegiatan berdasarkan jobdis/SOP.

4. Distribusi kaleng koin pada masyarakat

Distribusi kaleng koin kepada warga masyarakat yang sebelumnya telah memperoleh sosialisasi untuk selanjutnya diisi dalam jangka waktu satu bulan. Pengumpulan kaleng koin. Setelah satu bulan berada di masyarakat kaleng dikumpulkan dan dibuka kemudian dihitung dan hasilnya dikumpulkan menjadi satu

5. Pemanfaatan hasil koin

Pemanfaatan hasil kaleng koin. Fokus program gerakan koin NU peduli adalah : pendidikan, kesehatan, dan ekonomi. untuk itu, hasil koin di desa Ngronggot digunakan untuk : pelatihan wirausaha, 
santunan ( anak yatim maupun lansia ), bantuan modal usaha, bantuan orang sakit, bantuan sarana usaha

6. Monitoring

Monitoring. Monitoring dilakukan oleh stakeholders bersama penanggung jawab program, pendamping dan PC LAZIZNU. Monitoring ini dilakukan selama program berlangsung dan sekaligus dicarikan solusinya manakala ditemukan penyimpangan/hambatan 7. Evaluasi

Evaluasi. Evaluasi dilakukan oleh stakeholders utamanya oleh pendamping dan PC LAZIZNU kabupaten Nganjuk. Evaluasi dilaksanakan setelah program telah selesai dilaksanakan.

Pelaksaan program kegiatan poendampingan dapat ditam;ilkan sebagaimana table di bawah ini:

Tabel I

Pelaksaan kegiatan pendampingan Koinisasi

\begin{tabular}{llllr}
\hline NO & BULAN & TEMPAT & KEGIATAN & \\
\hline $\mathbf{1}$ & 1 s.d. 3 & di empat & Sosialisasi & program dan \\
& Januari 2019 & dusun & sekaligus & pembentukan \\
& & (Ngronggot & pengurus & dan petugas \\
& & Krajan, & pendistribusi koin. Pengurus \\
& & Dingin, & diambilkan dari pengurus \\
& & Brumbung, & ranting dan petugas dari ketua \\
& & dan Tempel) & RT setempat & \\
\hline
\end{tabular}




\begin{tabular}{|c|c|c|c|}
\hline NO & BULAN & TEMPAT & KEGIATAN \\
\hline & & $\begin{array}{l}\text { secara } \\
\text { bergiliran }\end{array}$ & \\
\hline 2 & $\begin{array}{l}\text { 14 Januari } \\
2019\end{array}$ & $\begin{array}{l}\text { di empat } \\
\text { dusun } \\
\text { (Ngronggot } \\
\text { Krajan, } \\
\text { Dingin, } \\
\text { Brumbung, } \\
\text { dan Tempel ) } \\
\text { secara } \\
\text { serempak }\end{array}$ & $\begin{array}{l}\text { Pendistribusian kaleng koin } \\
\text { kepada warga masyarakat di } \\
\text { desa Ngronggot. Jumlah kaleng } \\
\text { yang telah terdistribusi sebanyak } \\
1256 \text { kaleng }\end{array}$ \\
\hline 3 & $\begin{array}{l}15-17 \\
\text { Januari } 2019\end{array}$ & $\begin{array}{l}\text { Balai desa } \\
\text { Ngronggot }\end{array}$ & $\begin{array}{l}\text { Pelatihan wirausaha dengan } \\
\text { sasaran pemuda dan pemudi } \\
\text { desa Ngronggot sebanyak } 120 \\
\text { orang peserta yang mewakili } \\
\text { masing-masing dusun dengan } \\
\text { pembagian secara proporsional } \\
\text { kegiatan ini selalu dimonitor } \\
\text { oleh pendamping dan PC } \\
\text { LAZIZNU. Pelatihan ini } \\
\text { dikandung maksud untuk } \\
\text { menarik perhatian masyarakat } \\
\text { bahwa kegiatan koinisasi } \\
\text { memang ditangani secara serius }\end{array}$ \\
\hline 4 & $\begin{array}{l}8-11 \\
\text { Januari } 2019\end{array}$ & $\begin{array}{l}\text { Di masing- } \\
\text { masing dusun }\end{array}$ & $\begin{array}{l}\text { Pendampingan awal wirausaha } \\
\text { sebagai tindak lanjut pelatihan. }\end{array}$ \\
\hline
\end{tabular}




\begin{tabular}{|c|c|c|c|}
\hline NO & BULAN & TEMPAT & KEGIATAN \\
\hline & & & $\begin{array}{l}\text { Dalam pendampingan ini } \\
\text { ditemukan banyak hal menarik } \\
\text { di mana peserta memiliki } \\
\text { semangat untuk maju dan } \\
\text { kebanyakan ingin menjadi } \\
\text { wirausahawan }\end{array}$ \\
\hline 5 & $\begin{array}{l}2 \text { Februari } \\
2019\end{array}$ & $\begin{array}{l}\text { Kantor ranting } \\
\text { NU desa } \\
\text { Ngronggot }\end{array}$ & $\begin{array}{l}\text { Evaluasi kegiatan yang sudah } \\
\text { berjalan diikuti semua pengurus } \\
\text { dan petugas koin bersama } \\
\text { pendamping dan PC LAZIZNU. } \\
\text { Hasil evaluasi : dapat dikatakan } \\
\text { bahwa semua program berjalan } \\
\text { sesuai dengan rencana, namun } \\
\text { ada kendala dalam distribusi } \\
\text { kaleng di mana beberapa RT } \\
\text { belum bisa menerima program } \\
\text { karena sebelum ada program } \\
\text { koinisasi sudah ada program } \\
\text { sejenis yang dikelola oleh RT } \\
\text { setempat }\end{array}$ \\
\hline 6 & $\begin{array}{l}13-15 \\
\text { Februari } \\
2019\end{array}$ & $\begin{array}{l}\text { Di masing- } \\
\text { masing dusun }\end{array}$ & $\begin{array}{l}\text { Memonitor koinisasi oleh } \\
\text { petugas koin dengan cara } \\
\text { melakukan kunjungan ke warga } \\
\text { yang sudah mendapat kaleng } \\
\text { koin. Ditemukan data bahwa } \\
\text { semangat masyarakat untuk } \\
\text { berpartisipasi dalam koinisasi } \\
\text { cukup menggembirakan }\end{array}$ \\
\hline
\end{tabular}




\begin{tabular}{lllll}
\hline NO & BULAN & TEMPAT & KEGIATAN & \\
\hline 7 & $1-5$ Maret & Di masing- & Pendampingan warga yang \\
& 2019 & masing dusun & berkebutuhan khusus untuk \\
& & $\begin{array}{l}\text { menerima pelatihan ketrampilan } \\
\text { sebagai bekal hidup diikuti 23 } \\
\end{array}$ & & orang
\end{tabular}

\begin{tabular}{llll}
\hline $\mathbf{8}$ & $\begin{array}{l}\text { 19-20 Maret } \\
2019\end{array}$ & $\begin{array}{l}\text { Di masing- } \\
\text { masing dusun }\end{array}$ & $\begin{array}{l}\text { Audiensi dengan } \\
\text { masyarakat dalam memantapkan } \\
\text { program }\end{array}$ \\
\hline $\mathbf{9}$ & $\begin{array}{l}21-23 \\
\text { Maret 2019 }\end{array}$ & $\begin{array}{l}\text { Balai desa } \\
\text { Ngronggot }\end{array}$ & $\begin{array}{l}\text { Pelatihan home industri dengan } \\
\text { nara sumber dari BLK Nganjuk }\end{array}$ \\
\end{tabular}

10 24-25 Maret Di masing- Pendampingan praktik home 2019 masing dusun industry

1126 -27 Maret Di masing- Diskusi dengan stakeholders 2019 masing dusun terkait dengan program yang telah berjalan

\begin{tabular}{llll}
\hline 12 & $\begin{array}{l}\text { 26 -27 Maret } \\
2019\end{array}$ & $\begin{array}{l}\text { Di masing- } \\
\text { masing dusun }\end{array}$ & $\begin{array}{l}\text { Diskusi dengan stakeholders } \\
\text { terkait dengan program yang } \\
\text { telah berjalan }\end{array}$ \\
\hline 13 & 28 Maret & $\begin{array}{l}\text { Di masing- } \\
\text { masing dusun }\end{array}$ & $\begin{array}{l}\text { Pengumpulan kaleng koin dan } \\
\text { penghitungan hasil dalam bulan } \\
\text { Maret 2019 terkumpul Rp } \\
\end{array}$ \\
& & $\begin{array}{l}11.756 .200,00 \text { ( sebelas juta tujuh } \\
\text { ratus lima puluh enam ribu dua } \\
\text { ratus rupiyah ) }\end{array}$ \\
\hline $\mathbf{1 4}$ & 29 Maret & Balai desa & Musyawarah penggunaan hasil \\
\hline
\end{tabular}




\begin{tabular}{|c|c|c|c|}
\hline \multicolumn{3}{|c|}{$\begin{array}{ll}\mathrm{ISSN} & : 2656-5161 \\
\mathrm{e}-\mathrm{ISSN} & : 2686-0643\end{array}$} & Ats-sidanah \\
\hline NO & BULAN & TEMPAT & KEGIATAN \\
\hline & 2019 & Ngronggot & $\begin{array}{l}\text { koinisasi bulan Maret } 2019 \text {. } \\
\text { Dalam musyawarah disetujui } \\
\text { bahwa dana yang terkumpul } \\
\text { bulan Maret digunakan untuk } \\
\text { menyantuni anak yatim dan } \\
\text { duafa, bantuan modal, bantuan } \\
\text { sarana usaha, bantuan untuk } \\
\text { madrasah diniyah dan TPQ, } \\
\text { bedah rumah, bantuan orang } \\
\text { sakit, dana takiyah, } \\
\text { pemasangan penerangan jalan }\end{array}$ \\
\hline 15 & $\begin{array}{l}30 \text { Maret } \\
2019\end{array}$ & $\begin{array}{l}\text { Balai desa } \\
\text { Ngronggot }\end{array}$ & $\begin{array}{l}\text { Evaluasi dihadiri semua } \\
\text { stakeholder, pengurus, petugas } \\
\text { koin, pendamping dan PC } \\
\text { LAZIZNU. Dari hasil evaluasi } \\
\text { dapat diketahui bahwa semua } \\
\text { program berjalan dengan baik } \\
\text { dengan hasil yang memuaskan }\end{array}$ \\
\hline 16 & $\begin{array}{l}31 \text { Maret } \\
2019\end{array}$ & & $\begin{array}{l}\text { Penyusunan laporan oleh } \\
\text { pendamping }\end{array}$ \\
\hline
\end{tabular}

\section{Diskusi Data}

Dengan hadirnya Program Koin NU-Peduli telah menyadarkan masyarakat desa Ngronggot, bahwa mereka bisa melakukan sesuatu yang bermanfaat bagi dirinya dan juga masyarakatnya, yang sebelum program ini datang seolah-olah masyarakat apriori, pesimis dan 
menjustis bahwa mereka tidak bisa berubah lebih maju. Kenyataan ini adalah hasil perubahan mindset. Hal ini sesuai dengan ungkapan Plato,"Sumber setiap prilaku adalah pikiran. Dengan pikiran kita bisa maju atau mundur. Dengan pikiran kita bisa bahagia atau sengsara". Masyarakat juga sadar bahwa beribadah tidak hanya bersifat mahdhoh tetapi juga ibadah ghoiru mahdhoh sehingga terealisasi hablumminallah dan hablumminannas. Lebih jauh lagi mereka tahu bahwa Nahdlatul Ulama, yang selama ini dikenal hanya menangani kegiatan keagamaan ansih (tahlil, yasinan, pengajian, diba'an, barzanji, manaqib dan seputar itu ), kini tampil beda dengan kegiatan sosialnya berupa bantuan langsung yang dapat dinikmati masyarakat berupa bantuan pendidikan, bantuasn sosial, dan bantuan ekonomi. Hal ini sesuai dengan cita-cita pendiri Nahdlatul Ulama dengan programnya meliputi berbagai aspek kehidupan.

Bagi jam'iyyah Nahdlatul Ulama, ini merupakan bukti bahwa jami'yyah ini merupakan organisasi yang memiliki anggota yang jelas dan lebih mengembirakan lagi bahwa NU masih dipercaya masyarakat sebagai perekat bangsapengajian, pelatihan, pendampingan, santunan, pemberian bantuan ini diharapkan dapat menggugah kesadaran kita terutama warga masyarakat sekitar akan pentingnya menggali ilmu 
agama langsung dari sumbernya, dan juga menyadarkan masyarakat untuk berzakat dan bersedekah, serta menyadarkan akan pentingnya masyarakat mandiri.

Dan kami berharap kegiatan ini terdesiminasi ke desa-desa yang lain di seluruh kabupaten Nganjuk. Dan bagi Nahdlatul Ulama kegiatan ini disusul kegiatan-kegiatan yang lain. Dan alhamdulillah di masa khidmad ini muncul kerjasama LPPNU dan LPNU, RMI dan LP Ma'arif. LPBINU dan LAZIZNU

\section{Kesimpulan dan Saran}

Dengan selesainya pendampingan di desa Ngronggot terdapat beberapa implikasi kegiatan diantaranya (1) Kondisi masyarakat desa Ngronggot sebelum pendampingan meskipun semangat beragamanya dan solidaritas sosialnya sangat tinggi akan tetapi masih bersifat individual, (2) Bentuk kegiatan pendampingan yang dilakukan meliputi penyadaran akan potensi diri sehingga selalu berpikir positif, dan pelatihan vokasi berikut aplikasinya sehingga muncul interpreneurinterpreneur baru, (3) Setelah program pendampingan selesai, muncul kepercayaan masyarakat akan potensi diri baik secara ekonomi maupun keagamaan sehingga melahirkan kebersamaan untuk saling mendukung baik dalam kegiatan keagamaan maupun maupun social.

Vo 1. 2 No. 1, A pri 12020
Moh. Hasyim Afandi, Dkk | 81 gurnal Pengabdian Masyarakat 
Mengingat begitu besarnya manfaat pendampingan ini bagi masyarakat desa Ngronggot, maka program ini harus dilestarikan dan dikembangkan oleh stakeholder di desa setempat sehingga terjadi kesinambungan. Dengan besarnya partisipasi masyarakat dalam program ini, maka program yang dicanangkan harus bervariasi misalnya mendirikan klinik, mendirikan usaha ekonomi keumatan/NU Mart dan lain-alin. Sebagai bentuk pertanggungjawaban terhadap masyarakat dan supaya kepercayaan semakin tinggi perlu diterbitkan buletin bulanan.

Diharapkan kegiatan ini terdesiminasi ke desa-desa yang lain di seluruh kabupaten Nganjuk. Dan bagi Nahdlatul Ulama kegiatan ini harus disusul kegiatan-kegiatan yang lain. Dan alhamdulillah di masa khidmad ini muncul kerjasama LPPNU dan LPNU, RMI dan LP Ma'arif. LPBINU dan LAZIZNU

\section{Daftar Pustaka}

Alallah, Moh.Hasan Mutawakkil, Cerdas Spiritual dengan Metode Ikrar Berkarakkater ASWAJA, Probolinggo, Institut Ilmu KeislamanZainul Hasal Genggong, 2015. Elfiki, Ibrahim, Terapi Berpikir Positif,Jakarta, Zaman 
Mansur, Yusuf,2007, KUN FAYAKUN, Selalu ada Harapan di Tengah Kesulitan, Jakarta, Zikrul Hakim, 2009.

Muhaimin, DAKWAH ISLAM di tengah Transformasi Sosial, Surabaya, Karya Abditama, 2003

Robbins,Stephen P .Organization Theory, alih Bahasa Jusuf Udaya, Jakarta, Arcan, 1994.

TIM PPPA DARUL QUR'AN, Dahsyatnya Sedekan : Kumpulan Testimoni, Jakarta, PPPA Darul Qur'an,2010. 


\section{JURNAL}

\section{As-Sidanah}

Vol. 02 No. 1, April 2020 